\title{
Colonial Politics of Finding Equivalence: Interpreting 'Translation' and Anubad through Nineteenth Century English to Sanskrit/Bengali Dictionaries
}

RINDON KUNDU

\begin{abstract}
The proposed paper will be an attempt to explore the semantic domain of anubad in Bengal and how the term has been equated with 'translation' in the nineteenth century as well as how the term also differs from the 'standard' English equivalents. In this paper I intend to analyze different layers of the term 'translation' and anubad and different understandings in the respective activities. It will also note the discrepancies and rivalries in the process of equating 'translation' with the practice of anubad. This paper will also seek to trace how different meanings of anubad were in common currency and formed a part of the common parlance among the Bengalis who have adjusted and fitted the term in their language in a way so that it could very well deal with both the Sanskritik and Western understanding of the act of carrying over a text from one language to another.
\end{abstract}

Keywords: Anubad, Bengal, Translation, Nineteenth Century, Equivalents.

\section{Origin of the term 'Translation':}

The definition of the word 'translation' as "to transfer from one place or condition to another", came directly from the Latin word translationem (nominative translatio) which in middle of the twelfth century meant "carrying across, removal, transporting; transfer of meaning" (noun of action from past participle stem of transferre). Flipping through the pages of the English etymological dictionaries ranging from the nineteenth century to the twentieth, e. g., Chambers's 
Rindon Kundu

Etymological Dictionary of the English Language (1872) edited by James Donald or Klein's Comprehensive Etymological Dictionary of the English Language (1971) edited by Ernest Klein, with a critical insight bring us face-toface with the fact that the words "translate" and "transfer" have the same etymological roots. The relation between the two words dates back to their Latin usage. The word "transfer" came from Latin transferre which means "to bear across", "to carry over", "to bring through", "to transfer", "to copy" and "to translate". The prefix trans- means "across" and the root ferre means "to carry" . So, we can break both the words "translate" and "transfer" into trans+ferre/latum where latum is the past participle of the verb ferre which means "to carry" or "to bear".

To "translate" in the mid $14^{\text {th }}$ Century meant 'removal of a saint's body or relics to a new place', also 'rendering of a text from one language to another'. This meaning of the term has been derived from Old French translacion which means both 'translation of text' and 'also of the bones of a saint', etc. In the late $14^{\text {th }}$ Century, the word had links with the Old French word transferer. ${ }^{2}$ The fact that both the acts, one of the carrying over of a text from one language to another, from the source culture to the target culture and the other of the removal of the saint's body or relics were denoted by the same term gives a hint that text that was rendered in another language/culture was perhaps considered as holy as the bones of a saint. Therefore, the act of carrying over might have come to hold importance equivalent to that of a religious act, which if acceptable is holy, and if unacceptable becomes blasphemy and therefore amounts to debasing of the source text.

\footnotetext{
${ }^{1}$ See $<$ http://www.etymonline.com/index.php?term=transfer\&allowed_in_frame $=0>$

${ }^{2}$ See the following link:

$<$ http://www.etymonline.com/index.php?allowed_in_frame=0\&search=translation\&searchmo $\mathrm{de}=$ none $>$
} 
According to James Donald edited Chambers's Etymological Dictionary of the English Language, (1872), the term "translation" has a similar entry with an interesting addition: "the act of translating; removal to another place; the rendering into another language; a version". ${ }^{3}$ This notion of "removal to another place", much like that of the removal of the saint's bones and relics in the earlier periods, immediately reminds us of the idea of 'transmigration' which also has quite a similar meaning - "the passing into another state" ${ }^{4}$. This similarity is further reinforced by the fact that both the word "translation" and "transmigration" have religious connotations. Where "transmigration" denotes "the passage of the soul after death into another body", "translation" signifies "removal of a saint's body or relics to a new place". So, the notion of movement is inherent to the term translation which thereby implies a 'dislocation' and at the same time 'relocation' in a different place. In all the cases the process involves taking over from a place a thing originally belonged to another place, thereby infusing liveliness in the new place (as in case of transmigration the soul moving into another body gives life to it) and also adds a sense of spirituality to it since the place to which a saint's relics will be carried and where it will be contained will become the new shrine.

Since then there have been considerable developments in the western epistemological understanding of the process of translation. From the eras of the Bible translations in English of the fourteenth century ${ }^{5}$ to the present scholars and critics, the act of translation has been seen in various lights. Whereas

${ }^{3}$ See the entry of 'Translation' in Donald, James. Chambers's Etymological Dictionary of the English Language (1872) p. 528.

4 See the entry of 'Transmigration' in Donald, James. Chambers's Etymological Dictionary of the English Language (1872) p. 528.

${ }^{5}$ The first hand-written English language Bible manuscripts were produced in the 1380's AD by John Wycliffe. 
some translators stressed the importance of source language and welcomed its influence on the translated texts, others, in more recent discussions, have laid more stress on the target language and readers and believed that the texts should be translated according to the tastes and knowledge of the reading public so that they can derive complete pleasure out of it. But this dissertation will not go to the detailed discussion of that since the focus of it is to look at the process of translation as the plucking of the text from one cultural domain and planting it in another cultural context. The major focus of this paper is to explore the semantic domain of anubad in Bengal through analyzing lexicons and how the term has been equated with 'translation' in the nineteenth century and at the same time how this term differs from 'standard' English equivalent and notes the potential for discrepancies and rivalry among anubad and 'translation. Therefore, before going into the detailed study of the plays, a discussion on the classical Indian understanding of the idea of translation is important here.

\section{The Notion of 'Translation' as practised in India}

To begin with, the notion of translation as practised in India, it is important to begin with the contentions inherent in it. An idea of assimilating ideas and carrying them over to another language did exist in India. But whatever that practises might have been it did not exactly correspond to the western epistemological understanding of translation. The practice was more of a liberal activity which involved a repetition or representation of whatever that has already been said. The practice involved the gathering of ideas that existed before and then rehashing and representing them. Such works were hardly considered to be translations as we know of it today. Rather they were very much original and the skill of the author depended on how beautifully he could render the text and how receivable it becomes to the audience/readers. 
Since a language and therefore the literature is written in it cannot be separated from the culture in which it is embedded, the process of carrying over would also mean the confrontation between two cultures where the target culture and the source culture exchange both languages and ideas. The representation and re-rendering of the text depend much on how it is received by the reader-translator and his subjective understanding of both the practice of translation and that of his target audience for whom he does the translation.

With the advent of the British in India, the Orientalist's project and the translation practice taken up by the indigenous intellectuals in the colonial period did not leave the practice of translation just a simple blissful and pleasure giving exercise on the part of the translator but infused the practice with a political stance in a different paradigm.

The practice of "translation" within the boundaries of Fort William College and the kind of translations that were being done for the Calcutta School Book Society was a much serious business. It was for the first time that the Indian intellectuals felt the anxiety of being faithful to the source text and the responsibility towards it. They just could not twist and turn according to their own sweet will. The translated texts were meant to be the proper reflection of the original texts so that the readers who do not have access to the foreign language could get a true picture of the source text. But the practice gave prominence to the figure of the translator who, through his "prefaces" had to convince the readers about the origin of the source texts, the authenticity of translation and the strategies behind the practice.

But such a strict practice surprised the Indian intellectuals who were trained Sanskrit scholars and were habituated in the 
classical practice of anuvad/anubad. ${ }^{6}$ To understand their dilemma in the confrontation between the ideas of "translation" and "anuvad/anubad", a full-fledged discussion on the translation practice of an Indian translator as well as an etymological and historical understanding of the translation practice in India, becomes inevitable. It is more so because although today we use the word translation to describe the process of transporting a text from one language to another in India, the term is no way equivalent to the concepts of anuvad/anubad, anukaran, anusaran, bhasantar, chhaya, rupantar, and tarjuma which are the terms largely used in India to describe the process. With the advent of the colonizers, when the practice became widely equivalent, the indigenous intellectuals were faced with a dilemma. They were confronted with a new practice of carrying over a text from one language and culture to the other. But they also had a conscious understanding of the age-old practice of anuvad/anubad. It was at this juncture they adopted the word anuvad to describe their practice but injected in it a modernday understanding which included both the characteristics of the age-old practice and the western epistemological understanding of the translation. Thus, a clear understanding of the each of the words used in India for translation is essential to analyse the practice of a particular translator who is functioning in a cultural set-up that has much experimented with both the terms and the practice of translation. Sujit Mukherjee, in his seminal essay named "Personal Commitment: The Craft Not Sullen Art of Translation", has further demonstrated the long journey of the practice of translation from the pre-colonial period to the post-colonial

\footnotetext{
${ }^{6}$ In Bengali as well as Hindi script, vargiiya ba and antahstha va have been separate letters since olden times. The difference in pronunciation of anuvad and anubad is due to the difference of the usage of these two, ba/va between Sanskrit/Hindi and Bengali language.
} 
era. According to him, the translational relationship between Sanskrit and other bhashas i.e., Asamiya, Bangla, Gujrati, Hindi etc is one way from Sanskrit to the other Indian languages and not the other way round. During the Mughal period, the role of Persian in the translational process is different as it remains always as a ruler's language, not the ruling language. The Indian texts, which were written mostly in Sanskrit, have been translated into Persian. But with the advent of English, the situation of translation in India has taken a curious turn. On the one hand, the English people are learning Indian languages, on the other hand, the Indians are also learning the language of the coloniser and to make this process of learning institutionalised, both Fort William College and Serampore Mission Press were set up in the year 1800. But the curious point to note here is, as Sujit Mukherjee has demonstrated, "The first round of languages to be cultivated [at Fort William College] included Hindi and Urdu, Nangla and Marathi. Thus, was laid the foundation of translating, not from Sanskrit or Pali or Tamil, but from the bhashas, or the modern Indian languages" (Nair 2002: 27).

\section{Combing the Etymological Root of Anubad}

It is a rare coincidence that the term anuvad comes first in every discussion of Translation Studies in Indian context not merely for its alphabetic order but primarily for its usage in most of the Indian languages. Even with the advent of the British colonialism in India, this old Sanskrit term has been used as the close equivalent of the English term 'Translation' perhaps to 'encourage the belief that the practice is as old as the word' (Harmens 2006: 110). If we follow Sanskrit grammar then we will notice that the word anuvad is composed of Sanskrit prefix anu and the noun vada. Etymologically and Literally, Anuvad, as Avadesh K. Singh (2006) has proclaimed, stands for the 'subsequent' or 
Rindon Kundu

'following discourse' ( $а$ nu means 'following' and vad = discourse). So according to Singh:

...the term anuvad ... means 'subsequent discourse' (target text) based on a vad (discourse, i.e., source text). It presupposes an existing discourse, i.e., vad or source text. The vad and anuvad lead to the third stage, which we can term as samvad (dialogue) with one's own self and other(s) within and without. This dialogue or samvad impacts the self and the other in more ways than one in different historical periods. Attendant political, ideological and economic considerations notwithstanding, samvad become an instrument for the transformation of the self and the other ... (Singh: 206-7).

If we trace the evolution of the word anuvad/anubad through dictionaries and vocabularies, we will notice that the formation of the meaning of the term is taking place throughout the nineteenth century till the middle part of the twentieth century. The evolution of the word if studied critically will provide a fairly good idea on how this word has gradually (although somewhat erroneously) come to be used as a synonym of the modern practice of translation.

One of the earliest dictionaries in the history of Bengali lexicography, Henry Pitts Foster's A Vocabulary in Two Parts, Bongalee and English, And Vice Versa (Part II), published in 1802 , has recorded the meaning of anubad as "justification", "interpretation", "to expostulate" and anubadak as "interpreter". The interesting point here is the absence of the notion of Translation and instead of that verbs like "to interpret", "to justify" are being used to capture the Sanskrit idea of explanatory repetition. It alludes to the fact that something that has already been stated or written down can be repeated to justify its position, existence or argument, or to 
interpret the already existing in another more comprehensible language to grasp the meaning properly.

Probably the first Bengali to English dictionary, authored by a Bengali, is A Vocabulary, Bengalee and English, for the Use of Students (1810), written by Mohunpersaud Takoor, Assistant Librarian in the College of Fort William. The title itself clearly unpacks the purpose of the dictionary that it was meant for the advancement of colonial educational and the intended readers were the students of the College of Fort William. But the Vocabulary follows a different methodology as the words are listed according to subjects, i.e., 'Of God', 'Of Diseases', 'Parts of the Body', 'Of Diseases', 'Of House', 'Of Birds', 'Of trades', 'Of School', 'Verbs', 'Adverbs' etc and neither the word 'Translation' nor the terms like, 'Anuvad', 'Rupantar', 'Tarjuma' find a place in this dictionary. Read within the context of nineteenth century colonial politics of finding equivalence of the practice called 'translation' in Indian subcontinent, this lexical entry encourages us to view the practice of translation, mostly inclined to the western epistemological usage of the term, began within the walls of Fort William and was heavily used not only for understanding the culture of the indigenous population, which would have facilitated the ruling of the colonized, but was also featured as a major part of the pedagogical curriculum. The students were made to use translation as a means of learning the foreign language by the proponents of modern education in India and often their textbooks comprised of lessons translated from other languages.

William Carey's A Dictionary of the Bengalee Language (Vol. I), published in 1825, has been regarded as one of the most authoritative dictionaries in which the entire entry of anubad and its related words like anubadak, anubadakata, anubadi run as follows: 
Rindon Kundu

Anubad: a response, an abusive reply, a sentence which responds to some other sentence.

Anubadak: speaking in consequence of a prior circumstance, replying; a person who quotes the words of another.

Anubadakata: the circumstance of quoting a sentiment or passage from another.

Anubadi: replying, responding, and quoting (Carey: 3132).

So, the entry tells us that Carey is following the root meaning of the word anuvad in Sanskrit. It confirms the view that anubad is a kind of response, a reply in reference to something already said, an explanatory reiteration, quoting some other's speech/text in an exact manner. So this entry fits with the oral tradition of Indian culture where the early religious texts i.e., the four Vedas existed over a thousand years without ever having been written down and for that reason they have been called 'sruti' (hearing) as well as the person who is a scholar of four Vedas has been referred as 'srutidhor' (capable of remembering whatever he hears). At the same time, it cannot be overlooked that the term also means vulgar reply also.

The entry also interprets the act of translation as a dialogic interaction of the translator with the writer of the source text. This, if read in the light of Mikhail Bakhtin's understanding of the dialogic, is a statement against monologism ${ }^{7}$. Hence, translation creates a room for alternative perspectives on truth. It is through dialogic interaction that the creativity of the

\footnotetext{
${ }^{7}$ The English terms 'dialogic' and 'dialogism' often refer to the concept used by the Russian philosopher Mikhail Bakhtin in his work of literary theory, The Dialogic Imagination (1975). Bakhtin contrasts the 'dialogic' and the 'monologic' work of literature. The dialogic work carries on a continual dialogue with other works of literature and other authors. It does not merely answer, correct, silence, or extend a previous work, but informs and is continually informed by the previous work.
} 
translator gets an opportunity of renewal and regeneration and can also converse and argue with the authoritative discourse or the master narrative. Such an act empowers the figure of the translator who as a reader interprets the text through his subjective reading of it and then through his translation, questions the author and also provides a reply to many of the questions raised in the source text. The act, therefore, enters into a dialogic mode where the translator picks up the conversation from where the author left in turn leaving room for another reader-translator figure to pick up from what he has left. The conversation between two conflicting voices of that of the author and the translator opens up opportunities of generating new meanings out of the already existing text which although is derived from the source text often goes beyond it. This way of looking at the act of translation definitely gives more importance to the subjectivity and receptivity of the reader-translator thereby giving a hard blow to the source text (or author) oriented understanding of the practice. So, here we can argue that according to Carrey's understanding of anubad as a term for translation has more potential than the word "translation". It is important to note that in Carrey's epistemology of absolute and objective truth creating a "room for alternative perspectives on truth" is not possible. However, 'the freedom to interpret' in the Indian languages allows it.

Tarachand Chukruburtee in his A Dictionary in Bengalee and English, printed at the Baptist Mission Press in1827, defines the term anubad as only repetition and nothing else. In the following year, Reverend William Morton published another dictionary, named, Dvibhasarthakabhidhan or A Dictionary of the Bengali Language with Bengali Synonyms and an English Interpretation (1828). The purpose of this dictionary becomes crystal clear from the acknowledgement page that this work has been compiled "for the propagation of the Gospel in foreign parts" and written "by the first missionary of their 
appointment to India and the first fruits of His auxiliary literary labours in that extensive field, is most humbly and respectfully dedicated" "to the most Reverend the President, the right Reverend and other members of the incorporated society". According to him, the term anubad is synonymous with punahkathan in Bengali and in English it means response, abusive reply, quotation. This time and again allusion to the idea of "abusive reply" as a way of interpreting what translation means is hard to deal with. Although in Bengali the meaning is "punahkathan" which simply and quite innocently means repetition, yet the negative and for that matter the disturbing English connotation keeps recurring in the subsequent dictionaries. Specifically, this meaning snatches away all the dialogic glory from the word and renders it as a threat to the source text. It provides more importance to the source text which is the only truth and views the practice of translation as a degrading and disgraceful act that perils the status of the source text and misuses and offences it.

Another remarkable dictionary of the nineteenth century $A$ Dictionary, Bengali and Sanskrit: Explained in English and Adapted for Students of Either Language to which is added an Index, Serving as a Reversed Dictionary, is, in fact, a BengaliEnglish bilingual dictionary published from London in 1833. It has been compiled by Graves C. Haughton. Besides Bengali scripts, Haughton has provided Devanagari scripts for Hindi users, Arabic scripts for Arabic and Persian users, and Roman script for English and Portuguese users. The entry of anubad and the corresponding words are almost similar to Carey's dictionary.

Anubad: 1. A reply, (particularly) an abusive reply. 2. Tautology or repetition. 3. An interpretation.

Anubadak: 1. Answering, replying. 2. Quoting the words of another person. 
Anubadi: 1. Replying, answering. 2. Quoting or repeating the words of another person (Haughton: 137).

Here too we can notice that the word 'translation' does not exist as an equivalent to the term anubad, rather G. C. Haughton has followed the Sanskrit connotation of the word. At the same time, it should be noticed that here too Haughton is suggesting 'reply' as a meaning of anubad but it is in particular 'an abusive reply'. Although previous compilers like, Takoor, Chukruburtee, Morton, Carey etc referred towards this abusive meaning of the term in a discussion but it is probably Haughton who considers this 'abusive reply' as the primary meaning of the term anubad.

Next in discussion is A Dictionary in Sanskrit and English, Designed for the Private Students and of Indian Colleges and Schools (1846) compiled by Rev. William Yates and published by the Baptist Mission Press, Calcutta. The intended readers of this dictionary, as mentioned in the title, are students learning at home as well as the students studying in schools and colleges. The entry on anuvad adds "Abuse, coincidence, tautology". The three meanings provided here gives three distinct understanding of the activity. "Abuse" of course alludes to the idea of degradation and reviling; "tautology" might refer on the one hand repetition, iteration, duplication, the saying of the same thing again and again in different words, but on the other hand it might also mean statements that are true by necessity or by virtue of their logical form. But interesting is the use of the word "coincidence" which brings in the idea of "time" into the activity. It might allude to the fact of corresponding in nature or in time of occurrence; that a body of work which is similar to that of the source text coexist simultaneously and concomitantly with complete synchronicity. 
Let us now discuss another major publication from the Baptist Mission Press, Calcutta, the Abridgment of Johnson's Dictionary, English and Bengali, peculiarly calculated for the Use of European and Native Students (1851) compiled by John Mendis. Interestingly enough if we go through the entries like 'explanation', 'illustration', 'defamation', 'narration', 'repetition', 'reiteration', 'reply', 'saying again', 'slander' etc. - all the possible meaning of the term anubad as mentioned in earlier dictionaries and vocabularies of different sorts, the word anubad does not exist in any of these entries mentioned above. If we look at the entry of 'translation' there too the term anubad is absent as its possible equivalent. The entry of the term translation and the corresponding words are as follows:

Translate: sthanantar (translocation, removal or transfer from one place to another place); bhasantar (translanguage, removal or transfer from one language to another); hastantar (transfer to another hand or possession or control, handing over); tarjama (paraphrasing).

Translation: bhasantar likhon (translanguage, writing or transferring from one language to another), tarjama (paraphrasing); sthanantar haon ba karon (being translocated or doing translocation, being removed or removing/being transferred or transferring from one place to another place).

Translator: bhasantar bhasarochok (translanguage writer or writer who writes in another language), bhasantar karta (person who transfers from one language to another) tarjamaarak (a person who does paraphrasing), mutjiram. (347)

Mistranslate: asuddha bhasantar (erroneous transferring from one language to another). 
Mistranslation: asuddha bhasantar kora (erroneously transferring from one language to another), bhul tarjama (incorrect paraphrasing) (Mendis: 213).

It is clearly evident that the meaning 'sthanantar' (translocation) refers to the notion of translation as 'carrying across' which came directly from the $12^{\text {th }}$ Century Latin word translationem and this refers to the spatial metaphor which is inherent into the etymology of the word 'translation'. The meaning 'hastantar' or 'handing over' is probably a new coinage as far as the etymological history of the word 'translation' is concerned. This meaning refers to the transference of power/possession from one hand to another and thus presumes 'an act of power' and sheds light on the process of translation as a powerful activity from both linguistic as well as social perspective. But handing over the baton from the hand of the predecessor to the successor would also mean that there is a notion of seeking permission from the author of the source text who if agrees on the idea of relocation of the text in terms of linguistic domain, with full consent will allow translator to work on his text. The translator is, therefore, the inheritor, who is entrusted with the responsibility of protecting and taking good care of the possession that has been handed over to him. This hints at the gradual creeping in of the idea of the anxiety that the translator would suffer from regarding the faithful representation or the source text and maximum adherence to it in order to shoulder his responsibility of sincerely carrying out the task that he is entrusted with.

The next dictionary in the discussion, Bengali and English Dictionary, for the Use of Schools (1856) published by School Book Society, Calcutta is important for the fact that probably for the first time the word 'translation' has been given a place in the entry of anubad along with the word 'repetition'. These two meanings of anubad from now on coexist with each other 
though they are radically different from each other. The word 'repetition', according to Cambridge Advanced Learner's Dictionary, means 'saying again' and thus it refers to renarration after a moment while the word 'translation' refers etymologically 'carrying across' or 'crossing the barrier'. So, the co-existence of 'repetition' and 'translation' in the same entry presupposes a fundamental contrast because 'repetition' is referring towards a 'temporal' metaphor while 'translation' is based on a 'spatial' metaphor.

Monier Williams in his magnum opus A Sanskrit - English Dictionary, Etymologically and Philologically Arranged with Special Reference to Greek, Latin, Gothic, German, AngloSaxon and Other Cognate Indo-European Languages (1872) has given a detailed entry of the term anuvad and its corresponding words. It follows as:

Anu-vāda: saying after or again, repeating by way of explanation, explanatory repetition or reiteration with corroboration or illustration, explanatory reference to anything already said, translation; any portion of the Brahmanas which comments on, explains or illustrates an injunction (vidhi) previously propounded, and which does not itself propound rules (...); confirmation; report, rumour, on dit; slander, reviling (emphasize mine).

Anu-vadāka(ikā)(am), or anu-vādin(ī)/ini(i): repeating with comment and explanation, corroborative, concurrent, conformable, in harmony with (...).

Anu-vādya(m): to be explained by an Anuvāda, to be made the subject of one; (...)

Anuvādya-tva(m): the state of requiring to be explained by an Anuvāda (Williams: 39).

The point to be noted here is that Monier-Williams also here includes 'translation' as an equivalent to the term anuvad. 
According to Trivedi ${ }^{8}$, no other cognate words listed by Monier Williams including the verbs anuvach and anuvad or the nouns anuvachana, anuvaka and anuvakya "specify in greater detail the main meaning of the word, "saying after or again, repeating..." (Hermans 2006: 111). The entry on anuvadika/anu-vadini, for example, begins with "repeating with comment and explanation". The entry on anu-vać adds: 'to repeat', 'reiterate', 'recite', 'speak after', 'reply'; the entry on anu-vaćana records: "speak after, repetition, reciting, reading; lecture; a chapter, a section; recitation of certain texts (mantra) in consequence of and in connection or conformity with injunctions (parisha) spoken by other priests." The entry on anu-rāk $\bar{a}$ adds "saying after, reciting, repeating, reading; a chapter of the Vedas, a subdivision or section; a compilation from the Rig or Yajur-vedas" while the entry on anu-vāćana echoes almost same with further clarification: "the act of causing to recite; the recitation of mantras or passages of the Rig-veda by the Hotri in obedience to the injunction (parisha) of the Adhvaryu priest (Monier-Williams 1872: 38-9). Trivedi argued that this "aberrant definition included by MonierWilliams: "translation"” "is wrong" and "unwittingly anachronistic" because none of the above cognate words, defined by Monier-Williams himself, "contain even a whiff of anything like 'translation"” (Hermans 2006: 111). According to him, "though anuvada did not mean 'translation' in Sanskrit, it had ... been appropriated to mean that in the modern Indian languages by the time Monier-Williams compiled his dictionary". As seen above that the term 'translation' already exists as an equivalent of anuvad/anubad in the dictionary published by the School Book Society, Calcutta.

\footnotetext{
${ }^{8}$ As underlined by Harish Trivedi in his essay "In Our Own Time, On Our Own Terms 'Translation' in India”.
} 
Rindon Kundu

One of the early monolingual Bengali dictionaries of the twentieth century was written by a Bengali - Subal Chandra Mitra's Adarsha Bangla Avidhan, published in 1906. The entry of the term anubad and other cognate words begin with a greater detail:

Anubad: 1. poschadkathan (repetition after); anukirton (reiteration); punah punah kathan (saying or narrating again and again); bhasantarkaran (translanguage); tarjuma (paraphrasing); anukaran (imitation), apobad (defamation); ninda (slander); jonosruti (hearsay); kutsitartho bakya (vulgar sentence); prasangsha (praise); 2. pratikulata (hostility); shatruta (enmity).

Anubadak: bhasantarak (a writer who writes in another language); poschadkathak (who speaks after); punah punah kathak (who speaks again and again); nindak (slanderer).

Anubadito: anubadjukto (anubad added); bhasantorito: jahar anubad kora hoiache - asuddha (suddha = anudito) (transferred into another language: where anubad has already done - impure (pure - anudito).

Anubadee: anubadkari (person who does anubad); sadrisyo (likewise), tulya (comparable), anurup (similar); suchak (indicator/index) (Mitra: 96).

The interesting fact to notice here is the absence of the term 'translation' as an equivalent of anubad which has already entered into the dictionaries by the School Book Society and Monier-Williams. So, we can argue that Mitra has kept the 'original' meaning intact though it has been already infected with the colonial imposition of 'translation' as a 'prospective' equivalent. 
According to Gyanendramohan Das in his edited Bangala Bhashar Abhidhan ${ }^{9}$ (Dictionary of Bengali Language), first published in the year 1917, the prefix anu means 'punah punah, sadrisha, manda ityadi' (repetition in general, alike, bad etc.) and the noun vada means 'bola' (to tell). So together it means, to quote Das:

1. bhasantar; tarjuma; ak bhasar artha ba bhab abya bhasay byaktokoron; translation. (translanguage; tarjuma; to reveal inner significance or meaning of one language to another) 2. anukaran. (imitation) 3. ninda; apobad. (to defame; to slander) 4. dosharop. (to blame) 5. birombona. (harassment) (Das: 55-6).

So here we notice that the term anubad has many different connotations ranging from translation from tarjuma to translanguage and from defame or slander other to harassment. This wide range of meaning suggests that to confine the Sanskrit/Bengali term anuvad within the boundary of 'translation' in the Western sense is in itself problematic. Another interesting fact that is bound to attract our attention is that the term also been equated with the term 'translation' though it is monolingual (Bengali - Bengali) dictionary. So, it suggests that the term 'translation' is now entering into the Bengali vocabulary and in near future, it becomes almost a part and parcel of the Bengali language. Another fact is that even at this time anuvad meant in a sense means "to slander", "to defame", "to harass" others. Unlike in the history of the evolution of the term translation in the Western concept where

\footnotetext{
9 According to Banglapedia, National Encyclopedia of Bangladesh, Jnanendra Mohan Das's Bangla Bhasar Abhidhan (Dictionary of Bengali Language) "brings innovation in respect of mono-lingual Bengali dictionary. It is fragmentary of two volumes; first published from Kolkata in the year of 1917 (its enlarged edition was published in 1937). As a matter of fact, the entries of this dictionary contained, were more in number than other dictionaries published earlier."
} 
it came to be associated with certain the religious and holy practices, in the Indian context the term had in it a negative sense of degrading, which if read cynically can come to mean a process that demeans a text to an undignified position. This is perhaps because the suffix "bad" in Bengali takes up prefix like "apo" and "bi" to become "apobad" (literally means to blame and defame a person) and "bibad" (literally means quarrel or conflict). If this connotation is associated with the act of translation, then the figure of the translator emerges as that of a literary villain who unlawfully enters into a discourse (bad) with the source text keeping close association with it and therefore engages in a conflict with the author and in the end, with the production of the translated text, defames him.

Rajsekhar Basu's Chalantika: Adhunik Bangabhasar Abhidhan (1930) is different from the dictionaries we have discussed so far not because it is smaller in size but because it is a collection of words that were in vogue in the contemporary society and were used quite often. As recorded in the Chalantika the term anubad means 'bhasantar' (translanguage), 'tarjuma' (paraphrasing), and 'punahkathan' (saying again). So it is evident that these meanings of anubad were in common currency and formed a part of the common parlance among the Bengalis who have by then adjusted and fitted the term in their language in a way so that it could very well deal with both the Sanskritik and Western understanding of the act of carrying over a text from one language to another.

The entry of Anuvad in Haricharan Bandyopadhyay's herculean achievement, Bangiya Sabda Kosh (1832), needs proper attention because it contextualises the term more deeply. It follows as:

1. kothito bishoyer punohkathan ba punorukti. (repetition or reiteration of something that has already been said) 2. anukkhon kathan ba anukirton. (re- 
narration or repetition after a moment of time), "likhito gronther jodi koro anuvad, tobe se gronther paiyye aswad". (if you repeat/reiterate the written text then the textual meaning can be relished/enjoyed) 3. siddha bostur upanyas ba kathan. (to communicate or re-narrate the text already realized/performed) 4. bidhiprapto bishoyer bakyantare anubachan ba punohkathan. 'Nyayasutra' (repeating or restating, in other words, the meaning of an injunction) 5. Bhasantare punohkathan, bhasantarkaran, tarjuma [translation] (Repetition in a different language, trans-language, paraphrasing) 6 . kutsitartho bakya, gaali, apobad ... (vulgar sentence, slander, defamation) 7. kingbodonti, jonosruti. (rumour, hearsay)

So here we get a chronological evolution of the word anuvad / anubad. The dictionary very well traces the history of the word and alludes to the fact that primarily it meant oral repetition/reiteration of something that has already been uttered and also as the above stated ancient shloka by Bhababhuti states that this practice provided a better and clearer understanding of what already been stated and/or written down for anyone who may not have heard it clearly or understood it rightly for the first time. The entry from the Sanskrit legal text 'Nyaysutra' clearly depicts that the word gets variously used not only in Sanskrit literary theories but also in legal and logical texts. The word has also been used in derogatory sense and from School Book Society's Bengali and English Dictionary, Calcutta to Monier William's A Sanskrit to English Dictionary or from Hariharan Bandyopadhyay's Bangiya Sabda Kosh to Gyanendramohan Das's Bangala Bhashar Abhidhan, all these semantic atlases depict that 'there existed a range of meaning than one overriding sense of the word'. Haricharan Bandyopadhyay's entry on the evolution clearly suggests that the present-day understanding that 
anuvad means a repetition in a language other than that it was originally composed (bhasantarer madhyome punohkathan) came into existence much later in the 19th century when the Indians had to look for a word that would carry essence of the term "translation" as it was used by the colonizers.

So in this context, on one hand, we can argue that translation has inherent within it an idea movement - a movement through space - a dislocation happens in the source language/culture and its relocation in the target language/culture. ${ }^{10}$ Anubad, on the other hand, as in the original Sanskrit meaning, has an idea of a movement through time. To put into Trivedi's argument,

However, etymologically speaking (and the etymology of $\operatorname{anuvad}(a)$ in both senses is of course just the same), there persists a conceptual contrast between anuvad and 'translation'. While 'translation' in the sense of 'carrying across' is based on a spatial metaphor, anuvad in the sense of repetition is, on the other hand, a temporal metaphor. To offer a hypothetical explanation, Europe may be no bigger than India in geographical terms and perhaps has fewer languages than India in that comparable expanse, but it has had, at least since the fall of the Roman empire, a more entrenched and chauvinistic tradition of linguistic nationalism, i.e., the one-language-one-nation paradigm. Thus a transaction between languages was visualized spatially in Europe, across boundaries, while in India, with a more effective Sanskritic hegemony serving to unite the different parts of the nation, all that was required was for everyone to say the same thing in the same language, though not necessarily at the same time ${ }^{11}$ (113).

${ }^{10}$ See Ch. 1 of Chatterjee, Chandrani. Translation Reconsidered: Culture, Genre and the "Colonial Encounter" in Nineteenth-Century Bengal.

11 See Trivedi, Harish. "In Our Own Time, On Our Own Terms 'Translation' in India". 
Having traced the etymological roots of both the terms translation and anubad, it can be concluded, as Trivedi argued, that there has been an "absence of the practice and perhaps the very concept of 'translation' as it is understood in the West, in the early history of Indian literature. ${ }^{12} \mathrm{We}$ can hear the similar echo alluding to this 'absence' in the essay "Towards an Indian Theory of Literary Translation", where Ayyappa Panikkar is also proclaiming:

Anuvad implies repetition or a repetitive way of explanation. The absence of an exact equivalent for the modern sense of translation in medieval Indian languages probably suggests that the Indian practice tolerated a good deal of creative deviance in the retelling or adaptation of a literary text. The prestige of the source text did not taunt or frighten the translator ${ }^{13}(40)$.

\section{Conclusion}

Read within the context of lexical analysis of the terms related to translation and anubad, the discussions encourage us to review the evolutionary process of colonial politics of finding equivalence of the term 'translation' in the concept of anubad. However, it can be understood from the discussion that the ancient understanding of the term anuvad had no relation with writing down. It mostly meant, as against the western practice, an oral exercise of reciting a text to grasp its meaning. Hope these terminological findings impinges on the further evolution of discourses and concepts regarding translation practices in India.

12 See Trivedi, Harish. "In Our Own Time, On Our Own Terms 'Translation' in India”.

13 See Panikkar, Ayyappa. "Towards an Indian Theory of Literary Translation", Mukherjee, Tutun (ed.) Translation from Periphery to Centerstage. 
Rindon Kundu

\section{References}

Bandyopadhyay, Haricharan. 1832. Bangiya Sabda Kosh (2 vols.). New Delhi: Sahitya Akademi.

Carey, William. 1825. A Dictionary of the Bengalee Language (Vol. I). Serampore: Mission Press.

Carey, William. 1825. A Dictionary of the Bengalee Language (Vol. II. Part I \& II.). Serampore: Mission Press.

ChatTerJee, ChANDRANI. 2010. Translation Reconsidered: Culture, Genre and the "Colonial Encounter" in Nineteenth-Century Bengal. Newcastle upon Tyne: Cambridge Scholars Publishing.

Chukruburtee, TARAChand. 1827. A Dictionary in Bengalee and English, Baptist Mission Press: Calcutta.

DAS, GyANENDRAMOHAN. 1917. Bangala Bhashar Abhidhan. Ilahabahad: Indian Press.

DONALD, JAMES. 1872. Chambers's Etymological Dictionary of the English Language. Edinburgh: W. \& R. Chambers.

Foster, Henry PitTs. 1802. A Vocabulary in Two Parts, Bongalee and English, and Vice Versa (Part II). Calcutta: P. Ferris Post Press.

Guha, Charuchandra. 1916. The Modern Anglo-Bengali Dictionary: A Comprehensive Lexicon of Bilingual Literary, Scientific and Technological Words and Terms (Vol. I). Dacca: Bengal Library.

GuHA, Charuchandra. 1919. The Modern Anglo-Bengali Dictionary: A Comprehensive Lexicon of Bilingual Literary, Scientific and Technological Words and Terms (Vol. III). Dacca: Bengal Library.

Haughton, Graves C. 1833. A Dictionary, Bengali and Sanskrit: Explained in English and Adapted for Students of Either Language to which is added an Index, Serving as a Reversed Dictionary. London: J. L. Cox and Son. 
Holquist, Michael. (ed.). 1981. The Dialogic Imagination: Four Essays by Mikhail Bakhtin. Texas: University of Texas Press.

KLEIN, ERNEST. 1966. A Comprehensive Etymological Dictionary of the English Language. New York: Elsevier.

MENDIS, JoHN. 1851. Abridgment of Johnson's Dictionary, English and Bengali, Peculiarly Calculated for the Use of European and Native Students. Calcutta: Baptist Mission Pres.

Mitra, Subal Chandra. 1906. Adarsha Bangla Avidhan. Calcutta: New Bengal Press.

MukherJee, Sujit. 2002. Personal Commitment: The Craft Not Sullen Art of Translation. In Rukmini Bhaya Nair (ed.), Translation, Text and Theory: The Paradigm of India. New Delhi: Sage.

PANIKKAR, AYYAPPA. 1998. Towards an Indian Theory of Literary Translation. In Mukherjee, Tutun (ed.), Translation from Periphery to Centerstage. New Delhi: Prestige.

Singh, Avadesh Kumar. 2006. Translation in/and Hindi Literature. Translation Today, $3(1 \& 2)$.

Trivedi, Harish. 2006. In Our Own Time, On Our Own Terms: 'Translation' in India. In Theo Harmans (ed.), Translating Others. Manchester: St. Jerome Publishing. WiLliams, MONIER. 1872. A Sanskrit-English Dictionary, Etymologically and Philologically Arranged with Special Reference to Greek, Latin, Gothic, German, Anglo-Saxon and Other Cognate Indo-European Languages. Oxford: Calderon Press. 